\title{
High Salt Intake and Risk of Chronic Bronchitis: The Copenhagen Male Study-A 10-Year Followup
}

\author{
Poul Suadicani, ${ }^{1}$ Hans Ole Hein, ${ }^{1,2}$ and Finn Gyntelberg ${ }^{1}$ \\ ${ }^{1}$ The Copenhagen Male Study, Epidemiological Research Unit, Department of Occupational and Environmental Medicine, \\ Bispebjerg University Hospital, Bispebjerg Bakke 23, 2400 Copenhagen, Denmark \\ ${ }^{2}$ Research Centre for Prevention and Health, Glostrup University Hospital, Copenhagen, Denmark
}

Correspondence should be addressed to Poul Suadicani, psua0001@bbh.regionh.dk

Received 27 April 2011; Accepted 27 June 2011

Academic Editors: A. Kurdowska, A. Miyazato, and T. Seemungal

Copyright (c) 2011 Poul Suadicani et al. This is an open access article distributed under the Creative Commons Attribution License, which permits unrestricted use, distribution, and reproduction in any medium, provided the original work is properly cited.

\begin{abstract}
Objective. The role of salt intake as a risk factor for asthma, bronchial hyperresponsiveness, and other bronchial symptoms has been addressed in a number of studies. Collectively, these studies indicate an increased risk of bronchial symptoms with high consumption of salt, but the issue remains controversial. We tested prospectively the hypothesis that salt intake would be an independent risk factor for chronic bronchitis (CB). Design. A 10-year prospective study of 2,183 men aged 46 to 65 years without any relevant lung symptoms at baseline. Main Outcome. Chronic bronchitis. Results. During the 10-year followup, the overall incidence of $\mathrm{CB}$ was $7.1 \%$ among men without any relevant lung symptoms at baseline. In a multiple logistic regression analysis, controlling for age, smoking habits, occupational dust exposure, alcohol use, and social class, the odds ratio associated with selfassessed high salt preference (reported by $24 \%$ ) was $1.6(1.1-2.4)$. Interpretation. The results suggest that salt restriction may prevent chronic bronchitis.
\end{abstract}

\section{Background}

The role of salt intake as a risk factor for asthma, bronchial hyperresponsiveness, and other bronchial symptoms has been addressed in a number of studies as reviewed by Mickleborough and Fogarty [1]. Collectively, these studies indicate an increased risk of bronchial symptoms with high consumption of salt. To our knowledge, no prospective epidemiological studies have specifically focused on dietary salt intake as a risk factor for chronic bronchitis (CB).

Recently, in a 16-year followup from the Copenhagen Male Study (CMS) using a baseline established in 1985-86 we showed that $\mathrm{CB}$ was a significant risk factor for lung cancer mortality. At baseline, self-assessed high salt intake was associated with a twofold higher prevalence of chronic bronchitis (CB) [2].

Accordingly, since in the CMS we have access to data making a prospective analysis possible, we decided to study if salt intake would be an independent predictor of chronic bronchitis. Furthermore, the available data would provide the opportunity to carry out an analysis, which may be considered a "natural experiment".
In short, the CMS is a closed cohort study of 5,249 gainfully employed men, which was established in 1970-71, at the time the men were 40 to 59 years old with a median age of 48 . One year later, all men were invited to participate in a reexamination using a similar method. In 1976, a postal questionnaire was carried out which was returned by more than 4,000 of the men, and in 1985-86 all survivors were invited to participate in a more comprehensive clinical examination.

From the postal questionnaire of 1976 as well as the 198586 clinical follow-up study, we had information available about the study participants' perception of their dietary salt preference and a number of questions on lung symptoms, tobacco habits, and history of occupational exposure to dust and fumes.

We tested in a 10-year followup the hypothesis that an association exists between self-assessed high salt intake and $\mathrm{CB}$ risk.

\section{Material and Methods}

\subsection{Design of the Copenhagen Male Study}

1970-71. Study baseline is established. 
1971-72. A one-year follow-up study using the same method as in 1970-71.

1976. A five-year followup by questionnaire only. This followup constitutes the baseline of the present paper.

1985-86. A 15-year followup inviting all survivors from the original baseline, including questionnaire and clinical examinations of all participants. Chronic bronchitis incidence used in the present paper was defined as prevalent chronic bronchitis in the 1985-86 study.

2.2. Patient Characteristics. The CMS was set up in 1970 71 as a prospective cardiovascular cohort study of 5,249 Caucasian men with a mean age of 48 years (range of 40 59). The examination comprised a short interview based on a previously completed questionnaire from which information was obtained on lifestyle including smoking habits [3,4]. Based on information about education and job profile, the men were subdivided into five social classes as previously described in detail [5].

2.3. Data from the 1976 Questionnaire-The Study Baseline. In 1976, a postal questionnaire study was carried out with a response rate of $78 \%$. Information was obtained on selfassessed salt intake, smoking habits, alcohol consumption, occupational dust exposure, and lower airway symptoms. These data were used for the incidence analysis of the present study.

2.3.1. Salt Intake. Salt intake was crudely measured based on a simple question: do you consider yourself more inclined to eat salty food than other people do? Answer options were yes or no.

2.3.2. Smoking Habits. Study participants reported whether they were current smokers or not.

2.3.3. Alcohol Consumption. Subjects reported on their average weekly consumption of alcohol, that is, number of beverages. One beverage was defined as one standard beer or one glass of wine.

2.3.4. Occupational Dust Exposure. Are you at your daily work exposed to dust or fumes? Answer options were yes or no.

2.3.5. Lower Airway Symptoms. Five questions were used, all with answer options "yes" or "no": (1) Do you cough when you wake up in the morning? (2) In wintertime do you cough many times during the day or at night? (3) Do you cough many times a day or during the night for a period of more than three months per year? (4) In wintertime do you cough up phlegm when you wake up in the morning? (5) Do you cough up phlegm during the night or during the day for a period of more than three months per year?
2.4. Data from the 1985-86 Followup. In 1985-86, a clinical follow-up study was carried out. All men from the 1970-71 study were traced by means of the Danish Central Population Register. Between June, 1985, and June, 1986, all survivors (except 34 emigrants) from the original cohort were invited to take part in this study; 3,387 men (75\%) agreed and gave informed consent; their mean age was 63 years (range 53-74). The 1985-86 study took place at The Glostrup Population Studies, Glostrup Hospital, University of Copenhagen. Each subject was interviewed about a previously completed questionnaire including standardized questions on chronic bronchitis and subjected to a clinical examination including measurement of peak expiratory flow with a Wright-McKerrow peak flow meter; for validation of tobacco use, a venous blood sample was taken for determination of the serum concentration of cotinine, a primary metabolite of nicotine.

2.4.1. Tobacco Smoking Habits. The men classified themselves as never smokers, previous smokers, or current smokers. As previously estimated by means of serum cotinine, the validity of tobacco reporting in the CMS was high [6].

2.4.2. Dietary Factors. Salt intake was crudely measured based on a simple question: do you use more salt in your food than other people do?

2.4.3. Outcome. In the $1985-86$ followup, based on a slightly modified version of the British Medical Research Council questionnaire on respiratory symptoms [7], the men were classified as having $\mathrm{CB}$ or not. $\mathrm{CB}$ was defined as cough or phlegm lasting 3 months or more for at least 2 years. The validity of the diagnosis was further supported by the peak flow measurements showing a significantly lower score, mean $(\mathrm{SD})=413(124) \mathrm{L} / \mathrm{min}$, among men with $\mathrm{CB}$ than among others, $503(88) \mathrm{L} / \mathrm{min}, P<0.001$.

2.4.4. Eligible for Study. Men who could be classified in the 1985-86 clinical followup according to the criteria for CB as defined by the British Medical Research Council, were 3,330 men. Of these 3,330 men, 2,870 men, $86.2 \%$, had participated in the 1976 postal questionnaire and answered the question on salt intake; 2,183 of these men, $76 \%$, reported no lung symptoms at the 1976 baseline and were considered eligible for the study of incidence of CB from 1976 to 1986.

2.4.5. Statistical Analysis. Basic statistical analyses, including unpaired $t$-test, Chi-squared analysis, and multiple logistic regression analysis, were performed. Odds ratios were calculated by taking the natural $\log e$ raised to the regression coefficient for the variable of interest in separate multiple logistic regression with stepwise backward elimination of variables and the maximum likelihood ratio method [8]. Goodness of fit was ascertained using the Hosmer-Lemeshow test [8]. For all analyses, a two-sided probability value of $P<0.05$ was a priori taken as significant. 
TABLE 1: Baseline characteristics (1976) of men with high self-assessed salt intake (high salt preference) and others.

\begin{tabular}{|c|c|c|}
\hline & High salt intake $^{\#}$ & Others \\
\hline Subjects $n$ & 701 & 2169 \\
\hline Age yrs & $53.0 \pm 5.1$ & $52.9 \pm 5.1$ \\
\hline \multicolumn{3}{|l|}{ Smoking } \\
\hline Current smoking & 68.8 & $60.6^{\# \#}$ \\
\hline Smoking 1970/71 & 74.6 & $65.5^{\# \#}$ \\
\hline \multicolumn{3}{|l|}{ Alcohol use } \\
\hline \multicolumn{3}{|l|}{ Alcohol, beverages/week } \\
\hline $0-5$ & 51.2 & 60.6 \\
\hline $6-20$ & 39.8 & $33.8^{\# \#}$ \\
\hline $21+$ & 9.1 & 5.6 \\
\hline Occupational dust and fumes exposure & 27.1 & $21.7^{\# \#}$ \\
\hline \multicolumn{3}{|l|}{ Other characteristics } \\
\hline Low social class (IV/V) & 52.6 & 50.2 \\
\hline \multicolumn{3}{|l|}{ Lower airway symptoms } \\
\hline \multicolumn{3}{|c|}{ Do you cough when you wake up in the morning? } \\
\hline$\%$ yes & 13.8 & 11.9 \\
\hline \multicolumn{3}{|c|}{ In wintertime do you cough many times during the day or at night? } \\
\hline$\%$ yes & 10.2 & $8.1^{+}$ \\
\hline \multicolumn{3}{|c|}{$\begin{array}{l}\text { Do you cough many times a day or during the night for a period of more than three months per } \\
\text { year? }\end{array}$} \\
\hline$\%$ yes & 6.7 & 5.4 \\
\hline \multicolumn{3}{|c|}{ In wintertime do you cough up phlegm when you wake up in the morning? } \\
\hline$\%$ yes & 18.4 & $15.7^{+}$ \\
\hline \multicolumn{3}{|c|}{$\begin{array}{l}\text { Do you cough up phlegm during the night or during the day for a period of more than three } \\
\text { months per year? }\end{array}$} \\
\hline$\%$ yes & 6.1 & 5.6 \\
\hline
\end{tabular}

Data are presented as mean $\pm \mathrm{SD}$ or percentages. ${ }^{\#}$ : high salt preference; ${ }^{+}: P<0.10 ;{ }^{\# \#}: P<0.01 ; P$ value of Chi-squared test or unpaired $t$-test (age).

2.4.6. Ethics. Each participant was informed that all personal data were confidential and gave written consent about participation. The study has been approved by the committee for ethics in medical research in the County of Copenhagen.

\section{Results}

Table 1 shows baseline characteristics (1976) of men with high self-assessed salt intake (high salt preference) and others. Those reporting that they liked salty food more than others were more likely to be smokers, had a higher consumption of alcohol, and were more frequently exposed to dust and fumes at their work. Despite these characteristics, only a weak and not significant association was found to social class. Also lung symptoms were more frequent among men who reported a high salt intake, although overall differences were small and none of the associations reached statistical significance.

Table 2 shows the association between the baseline factors presented in Table 1 with incidence of chronic bronchitis during the 10-year incidence study. Men with any of the lung symptoms presented in Table 1 were excluded from the analysis. Men who were diagnosed with CB in 1985-86 were a little older, they were much more often high salt users, they smoked more often, and they were more often occupationally exposed to dust or fumes. Also they more often belonged to the lower social classes, although the difference was not statistically significant.

Table 3 shows the result of a multiple logistic regression analysis of men without bronchitis symptoms at baseline. Current smoking, occupational dust and fumes exposure, and high salt intake in 1976 were significant predictors of chronic bronchitis in 1985-86; the odds ratio associated with salt intake was $1.6(1.1-2.4)$.

Table 4 shows the result of a prospective analysis 19761986 including men without lung symptoms in 1976 indicating bronchitis, $n=2,183$, according to self-assessed salt intake in 1976 and 1986. As seen in the table, the crude incidence of $\mathrm{CB}$ increased from 5.8\% among men with low salt intake in 1976 as well as 1986 to $15.9 \%$ among men with a high salt intake at both points in time. Adjusting for age, smoking, occupational dust exposure, and social class had no major influence on the results. Risk of CB was three times higher among men who had a high salt intake both in 1976 and 1986 compared to those with low salt intake.

As presented in the lower part of the table, to further ascertain that smoking at the time of CB diagnosis in 1986 
TABle 2: Association of baseline characteristics 1976 with chronic bronchitis ten years later among men with no relevant lung symptoms at baseline, $n=2,183$.

\begin{tabular}{|c|c|c|c|}
\hline & \multicolumn{3}{|c|}{ Chronic bronchitis in 1985-86 } \\
\hline & + & \multicolumn{2}{|c|}{-} \\
\hline Subjectsn & 155 & \multicolumn{2}{|c|}{2028} \\
\hline Age yrs & $53.1 \pm 5.1$ & \multicolumn{2}{|c|}{$52.7 \pm 5.1^{+}$} \\
\hline High salt intake & 33.8 & \multicolumn{2}{|c|}{$22.9^{\# \#}$} \\
\hline \multicolumn{4}{|l|}{ Smoking } \\
\hline Current smoking & 76.8 & \multicolumn{2}{|c|}{$54.6^{\# \#}$} \\
\hline Smoking 1970/71 & 79.4 & \multicolumn{2}{|c|}{$61.2^{\# \#}$} \\
\hline \multicolumn{4}{|l|}{ Alcohol use } \\
\hline \multicolumn{4}{|l|}{ Alcohol, beverages/week } \\
\hline $0-5$ & 58.1 & \multicolumn{2}{|c|}{60.9} \\
\hline $6-20$ & 36.8 & \multicolumn{2}{|c|}{34.5} \\
\hline $21+$ & 5.2 & \multicolumn{2}{|c|}{4.6} \\
\hline $\begin{array}{l}\text { Occupational dust and fumes } \\
\text { exposure }\end{array}$ & 34.4 & \multicolumn{2}{|c|}{$20.3^{\# \#}$} \\
\hline \multicolumn{4}{|l|}{ Other characteristics } \\
\hline Low social class (IV/V) & 56.1 & \multicolumn{2}{|c|}{$47.8^{++}$} \\
\hline \multicolumn{4}{|c|}{$\begin{array}{l}\text { Data are presented as mean } \pm \mathrm{SD} \text { or percentages. }{ }^{\#}: \text { high salt preference; }{ }^{++} \\
P<0.05{ }^{+}: P<0.10{ }^{\# \#}: P<0.01 P \text { value of Chi-squared test or unpairec } \\
t \text {-test (age). }\end{array}$} \\
\hline \multicolumn{4}{|c|}{$\begin{array}{l}\text { TABLE 3: Prospective analysis } 1976-1986 \text { including only men who } \\
\text { in } 1976 \text { had no lung symptoms indicating bronchitis, } n=2,183 \text {. } \\
\text { Self-assessed high salt intake } 1976 \text { as a predictor of chronic } \\
\text { bronchitis in 1985-86. Variables are ranked according to strength of } \\
\text { statistical association with chronic bronchitis following multivariate } \\
\text { adjustment in an age-adjusted multiple logistic regression analysis. }\end{array}$} \\
\hline & \multicolumn{3}{|c|}{ Chronic bronchitis in $1985-86$} \\
\hline & Odds ratio & $95 \% \mathrm{CI}$ & $P$ \\
\hline Current smoking 1976 versus not & 2.6 & $1.7-3.8$ & $<0.001$ \\
\hline $\begin{array}{l}\text { Occupational dust (and fumes) } \\
\text { exposure } 1976 \text { versus not }\end{array}$ & 1.9 & $1.3-2.8$ & $<0.001$ \\
\hline High salt intake 1976 versus not & 1.6 & $1.1-2.3$ & 0.009 \\
\hline $\begin{array}{l}\text { Low social class (IV/V) versus } \\
\text { higher }\end{array}$ & 1.4 & $0.96-1.9$ & 0.08 \\
\hline
\end{tabular}

Excluded from the final model $(P>0.10)$ : alcohol use.

did not confound the association, we made a further analysis including only men who were smokers in 1976 as well as 1986. The relative impact of salt habits on CB incidence was practically the same for this group as for the whole group presented in the upper part of the table with a threefold higher risk among those with a steady high or a change from low to high salt use compared to smokers with a steady low or change from high to low salt use.

\section{Discussion}

Self-assessed high salt intake was associated with a higher incidence of chronic bronchitis in a ten-year prospective study, taking into account smoking habits, alcohol consumption, occupational dust exposure, and social class in the analyses. Furthermore, the design of this study made it possible to look at data as if an intervention trial had been carried out. During the followup exposure to the risk factor under study, that is, self-assessed salt intake, changed among a sufficient number of men as to allow us to analyze if these changes were associated with changes in bronchitis incidence also. The observations that reducing self-assessed salt intake was on the one hand associated with a reduced risk of $\mathrm{CB}$, and that increasing or maintaining a high salt consumption on the other hand conferred a three times higher risk of $\mathrm{CB}$ support a causal relationship.

4.1. High Salt Intake. Are the new findings biologically plausible? $\mathrm{CB}$ is primarily an inflammatory condition involving various immune responses, and smoking is the number one risk factor and the first target of intervention against the disease. However, as illustrated in Table 2, factors other than smoking are associated with chronic bronchitis, factors associated to lifestyle as well as occupation. The findings with respect to salt intake observed in this paper are in agreement with observational, and human and animal experimental studies on the relationship between bronchial asthma and salt intake as reviewed by Mickleborough [1]. Animal experimental studies by the same author demonstrated that salt loading affected leukotriene metabolism involved in bronchial reactivity [9]. In a human experimental study, a high salt diet also induced a stronger inflammatory response compared to a low salt diet, among a group of men exposed to exercise [10]. Another experimental study suggested that salt manipulation modified the induced sputum supernatant IL-1b and IL-8 concentration after exercise [11]. These cytokines are associated with neutrophilic inflammation-a typical feature of CB and more rare in asthma [12].

As reviewed, morbidity and mortality caused by chronic obstructive pulmonary disease (COPD) has increased worldwide during recent decades [13]. Although tobacco smoking is the undisputed risk factor number one for COPD, also nutritional factors, including increased consumption of salt, have been suggested as risk factors contributing at least to the concomitant increase in another also basically inflammatory pulmonary condition, asthma. Mickleborough and Fogarty recently reviewed the association between sodium intake and asthma or airway hyperresponsiveness [1]. Based on the results of observational epidemiological studies and experimental studies, they concluded that although study results were not completely consistent, a low sodium diet for a period of only a few weeks may improve lung function in adults with asthma, while sodium loading appears to have a detrimental effect. Although asthma and COPD share several common clinical manifestations including bronchial inflammation and bronchial hyperresponsiveness, only one study has specifically addressed the issue of salt and CB [14]. That study focused on the ratio of sodium and potassium as a risk factor for $\mathrm{CB}$ among men, finding that sodium intake was not per se associated with CB. A precondition for an association to $\mathrm{CB}$ was a concomitant low intake of potassium. 
TABLE 4: Prospective analysis 1976-1986 including only men who in 1976 had no lung symptoms indicating bronchitis, $n=2,183$ according to self-assessed salt intake in 1976 and 1985-6 and smoking characteristics. Various forced entry multiple logistic regression analyses using different adjustment criteria.

\begin{tabular}{|c|c|c|c|c|}
\hline & Low/Low & High/Low & Low/High & High/High \\
\hline All men, $n=2,183$ & \multicolumn{4}{|c|}{ Self-assessed salt intake in 1976 and 1986, respectively } \\
\hline$N$ & 1582 & 333 & 63 & 176 \\
\hline Crude CB incidence, \% & $5.8 \%$ & $7.2 \%$ & $14.3 \%$ & $15.9 \%$ \\
\hline \multicolumn{5}{|l|}{ Odds ratio, adjustment for: } \\
\hline (1) age & $1^{\mathrm{a}}$ & $1.25(0.78-1.99)$ & $2.81(1.34-5.88)^{* *}$ & $3.08(1.95-4.86)^{* * *}$ \\
\hline (2) + smoking 1976 & $1^{\mathrm{a}}$ & $1.19(0.74-1.90)$ & $2.89(1.37-6.10)^{* *}$ & $2.76(1.74-4.39)^{* * *}$ \\
\hline (3) + occupational dust exp. & $1^{\mathrm{a}}$ & $1.19(0.74-1.92)$ & $3.02(1.41-6.45)^{* *}$ & $2.85(1.78-4.55)^{* * *}$ \\
\hline$(4)+$ social class & $1^{\mathrm{a}}$ & $1.21(0.75-1.95)$ & $3.15(1.47-6.77)^{* *}$ & $2.84(1.77-4.53)^{* * *}$ \\
\hline $\begin{array}{l}\text { Smokers in both } 1976 \text { and 1985-6, } \\
n=984\end{array}$ & \multicolumn{4}{|c|}{ Self-assessed salt intake in 1976 and 1986, respectively } \\
\hline$N$ & 683 & 161 & 29 & 111 \\
\hline Crude CB incidence, \% & $8.8 \%$ & $9.3 \%$ & $20.7 \%$ & $21.6 \%$ \\
\hline \multicolumn{5}{|l|}{ Odds ratio, adjustment for: } \\
\hline (1) age & $1^{\mathrm{a}}$ & $1.08(0.59-1.96)$ & $3.03(1.18-7.83)^{*}$ & $2.92(1.73-4.94)^{* * *}$ \\
\hline$(2)+$ occupational dust exp. & $1^{\mathrm{a}}$ & $1.03(0.56-1.89)$ & $2.96(1.14-7.71)^{*}$ & $2.97(1.74-5.06)^{* * *}$ \\
\hline$(3)+$ social class & $1^{\mathrm{a}}$ & $1.05(0.57-1.92)$ & $3.02(1.16-7.89)^{*}$ & $2.97(1.74-5.07)^{* * *}$ \\
\hline
\end{tabular}

In the present study, we found that men with a self-assessed high salt intake were more likely to be smokers. Furthermore, they had a higher intake of alcohol. These lifestyle factors are associated with increased occurrence of $\mathrm{CB}$ and were thus potentially confounding factors, yet unable to explain the association between self-assessed high salt intake and CB. In fact, it is quite surprising since a question on self-assessed high salt intake is a very crude measure of the actual total daily salt consumption; the strength of the true association between high salt intake and risk of CB may be even stronger than the present study could detect.

4.2. Methodological Considerations. In epidemiological studies, whether cross-sectional or prospective, it is necessary to consider potential bias, in particular bias related to measurements, inadequate confounder control, and selection. Would such sources of bias be able to explain the associations found?

Definition of CB was based on conventional criteria of the British Medical Research Council questionnaire for determining bronchitis. Information on smoking in the CMS has previously been validated by measuring serum cotinine [6]. Data on occupational exposure for dust was based on selfassessment. However, previous studies in the Copenhagen Male Study have shown a strong agreement between job titles and exposures likely to be associated with specific job functions [15]. Imprecision in the validity of exposure and outcome variables, and of potential confounders, cannot be excluded.

4.3. Conclusion and Perspectives. The results suggest that salt restriction may prevent chronic bronchitis. The present incidence study supports the idea that high salt intake is not only associated with asthma, bronchial hyperresponsiveness, and various other lung symptoms, but also with chronic bronchitis as conventionally defined. A pragmatic clinical implication would be to include information on salt preference from the bronchitis patient and take action accordingly.

\section{Authors' Contributions}

P. Suadicani declares that he participated in the planning of the paper, working out the focus of the paper, analysing all data, writing the first draft, discussing in plenum the results, and adjusting the manuscript, and that he has seen and approved the final version. H. O. Hein declares that he participated in the planning of the paper, working out the focus of the paper, discussing in plenum the results, and adjusting the manuscript, and that he has seen and approved the final version. F. Gyntelberg declares that he participated in the planning of the paper, working out the focus of the paper, discussing in plenum the results, and adjusting the manuscript, and that he has seen and approved the final version.

\section{Conflict of Interests}

The authors declare no conflict of interests.

\section{Acknowledgments}

This study received grants from The King Christian X's Foundation, The Danish Medical Research Council, The Danish Heart Foundation, and The Else \& Mogens WedellWedellsborg Foundation. P. Suadicani \& F. Gyntelberg are the guarantors of the paper. 


\section{References}

[1] T. D. Mickleborough and A. Fogarty, "Dietary sodium intake and asthma: an epidemiological and clinical review," International Journal of Clinical Practice, vol. 60, no. 12, pp. 16161624, 2006.

[2] P. Suadicani, H. O. Hein, and F. Gyntelberg, "ABO phenotypes and inflammation-related predictors of lung cancer mortality: the Copenhagen Male Study - a 16-year follow-up," European Respiratory Journal, vol. 30, no. 1, pp. 13-20, 2007.

[3] F. Gyntelberg, "One and two years incidence of myocardial infarction in Copenhagen males aged 40-59," Danish Medical Bulletin, vol. 22, no. 2, pp. 81-84, 1975.

[4] F. Gyntelberg, "Physical fitness and coronary heart disease in male residents in Copenhagen aged 40-59," Danish Medical Bulletin, vol. 20, no. 1, pp. 1-4, 1973.

[5] P. Suadicani, H. O. Hein, and F. Gyntelberg, "Socioeconomic status, $\mathrm{ABO}$ phenotypes and risk of ischaemic heart disease: an 8-year follow-up in the Copenhagen Male Study," Journal of Cardiovascular Risk, vol. 7, no. 4, pp. 277-283, 2000.

[6] P. Suadicani, H. O. Hein, and F. Gyntelberg, "Serum validated tobacco use and social inequalities in risk of ischaemic heart disease," International Journal of Epidemiology, vol. 23, no. 2, pp. 293-300, 1994.

[7] C. M. Fletcher, P. C. Elmes, A. S. Fairbairn, and C. H. Wood, "The significance of respiratory symptoms and the diagnosis of chronic bronchitis in a working population," British Medical Journal, vol. 2, no. 5147, pp. 257-266, 1959.

[8] D. W. Hosmer and S. Lemeshow, Applied Logistic Regression, Wiley-Interscience, New York, NY, USA, 1989.

[9] T. D. Mickleborough, R. W. Gotshall, J. Rhodes, A. Tucker, and L. Cordain, "Elevating dietary salt exacerbates hyperpneainduced airway obstruction in guinea pigs," Journal of Applied Physiology, vol. 91, no. 3, pp. 1061-1066, 2001.

[10] T. D. Mickleborough, M. R. Lindley, and S. Ray, "Dietary salt, airway inflammation, and diffusion capacity in exerciseinduced asthma," Medicine and Science in Sports and Exercise, vol. 37, no. 6, pp. 904-914, 2005.

[11] S. Hashimoto, K. Matsumoto, Y. Gon, T. Nakayama, I. Takeshita, and T. Horie, "Hyperosmolarity-induced interleukin-8 expression in human bronchial epithelial ceils through p38 mitogen-activated protein kinase," American Journal of Respiratory and Critical Care Medicine, vol. 159, no. 2, pp. 634640, 1999.

[12] E. R. Bleecker, "Similarities and differences in asthma and COPD: the Dutch hypothesis," Chest, vol. 126, no. 2, pp. 93S95S, 2004.

[13] H. A. Smit, L. Grievink, and C. Tabak, "Dietary influences on chronic obstructive lung disease and asthma: a review of the epidemiological evidence," Proceedings of the Nutrition Society, vol. 58, no. 2, pp. 309-319, 1999.

[14] J. Schwartz and S. T. Weiss, "Dietary factors and their relation to respiratory symptoms. The Second National Health and Nutrition Examination Survey," American Journal of Epidemiology, vol. 132, no. 1, pp. 67-76, 1990.

[15] P. Suadicani, H. O. Hein, and F. Gyntelberg, "Do physical and chemical working conditions explain the association of social class with ischaemic heart disease?" Atherosclerosis, vol. 113, no. 1, pp. 63-69, 1995. 


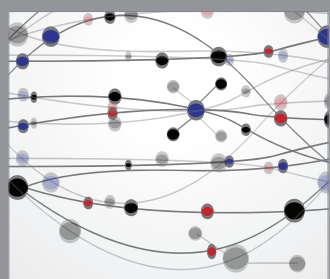

The Scientific World Journal
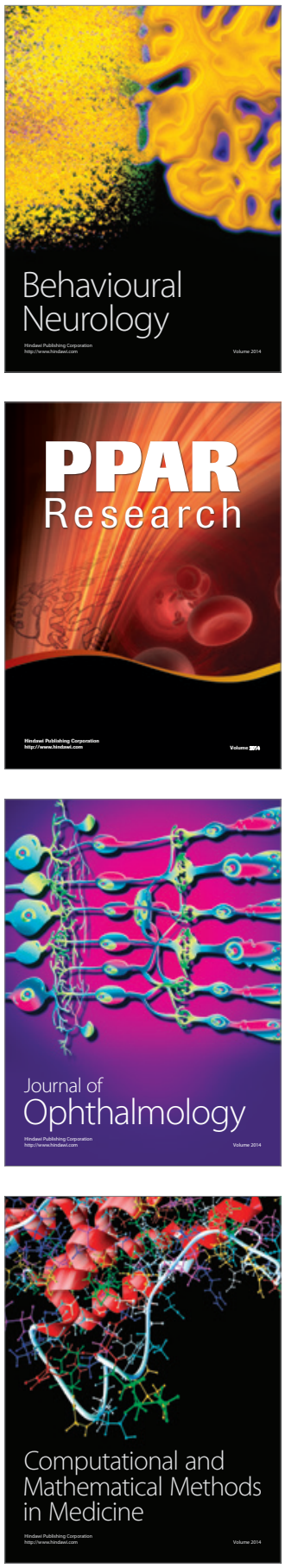

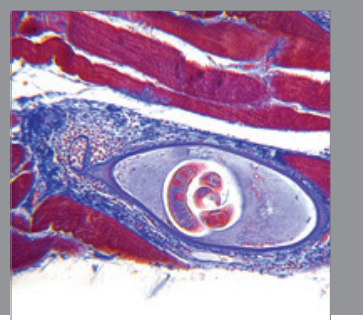

Gastroenterology

Research and Practice
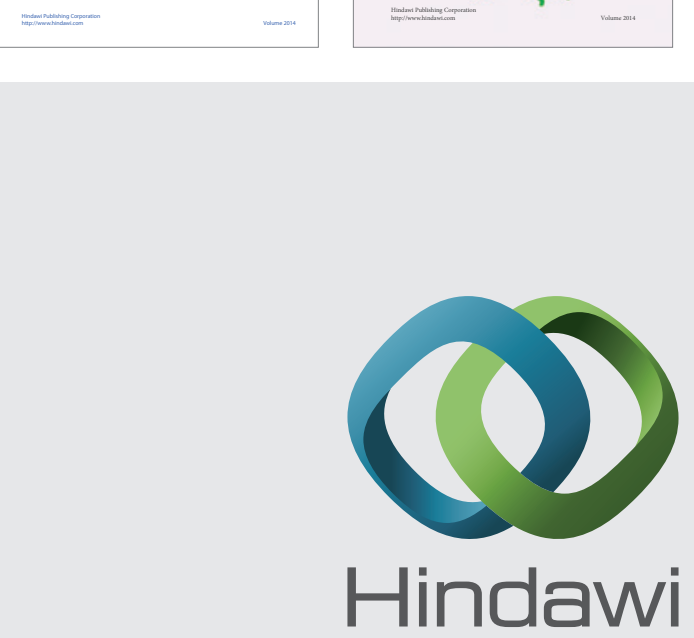

Submit your manuscripts at

http://www.hindawi.com
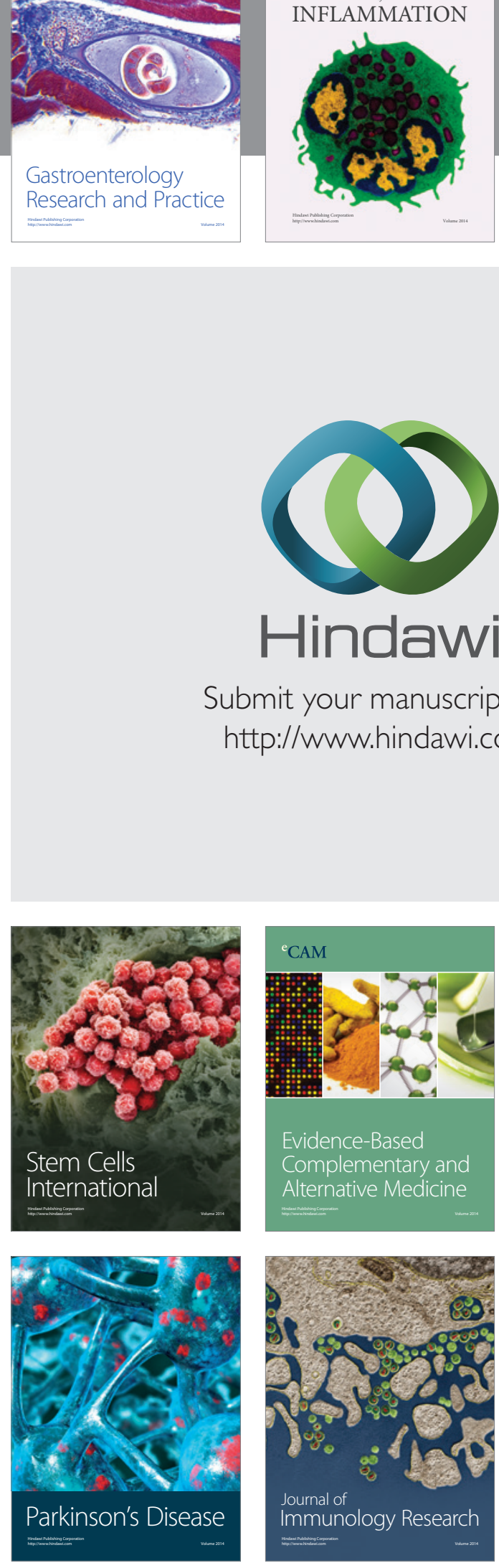

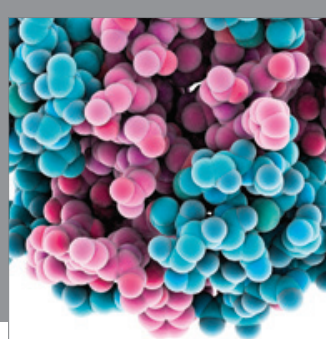

Diabetes Research
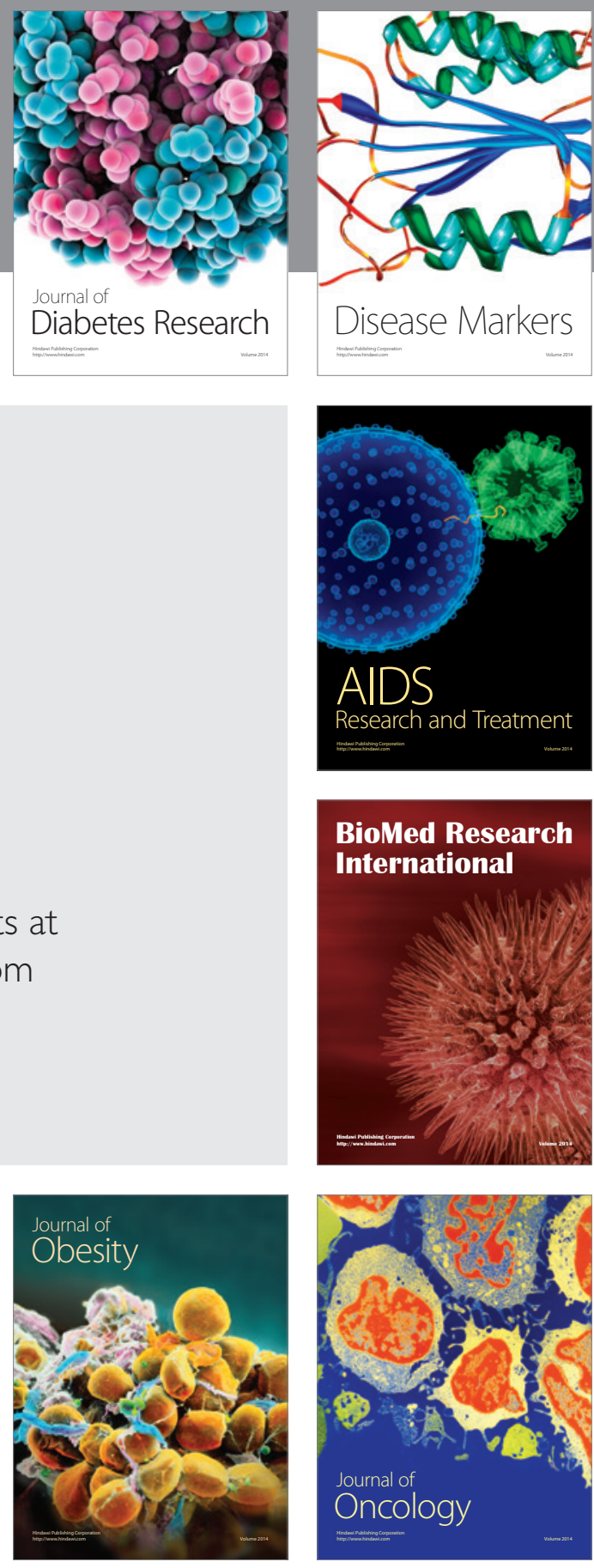

Disease Markers

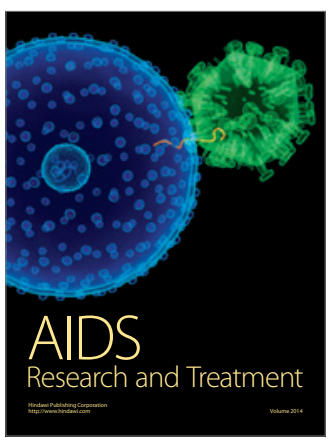

BioMed Research

International
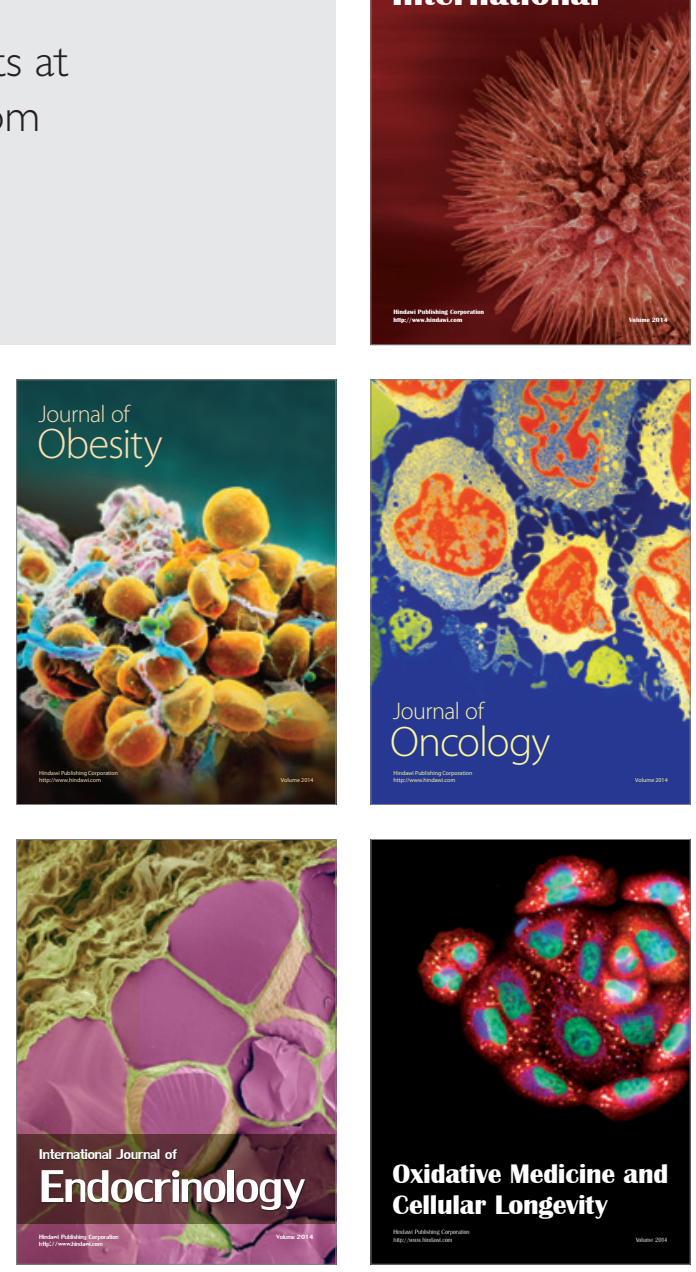